\title{
Wpływ obróbki cieplnej na własności i strukturę stali 4330V
}

\author{
Effect of heat treatment on the properties \\ and structure of steel $4330 \mathrm{~V}$
}

\begin{abstract}
Streszczenie
W artykule opisano wpływ obróbki cieplnej polegającej na wygrzewaniu stali $w$ zakresie temperatur $100 \div 900{ }^{\circ} \mathrm{C}$ na strukturę i własności stali ulepszonej cieplnie 4330V. Celem pracy było zbadanie zachowania się stali przy długim wygrzewaniu bez atmosfery ochronnej w piecu oporowym. Jest to ważny aspekt podczas wykorzystania tego typu stali, gdy są one dostarczane do odbiorcy w stanie gotowym po hartowaniu i odpuszczaniu. Dzięki temu można stwierdzić, do jakich temperatur możliwe jest podgrzanie stali $4330 \mathrm{~V}$ w procesach łączenia takich jak spawanie. Po przeprowadzonym procesie wygrzewania badanie próbki zostały przebadane pod kątem zmian strukturalnych, twardości i udarności. Przeprowadzane badania wykazały zmniejszenie własności po przekroczeniu temperatury $600^{\circ} \mathrm{C}$ podczas wygrzewania. Uzyskano znaczny spadek twardości do poziomu 275 HV. W wyniku wygrzewania w temperaturze ponad $800{ }^{\circ} \mathrm{C}$ nastąpiło zahartowanie materiału w powietrzu.
\end{abstract}

\begin{abstract}
The article describes the effect of heat treatment of steel in the temperature range of $100 \div 900{ }^{\circ} \mathrm{C}$ on the structure and properties of tempered $4330 \mathrm{~V}$ steel. The aim of the study was to investigate the behavior of steel under long heating without a protective atmosphere in the resistance furnace. This is an important aspect when you use this type of steel, when they are delivered to the customer in the running order after hardening and tempering. This allows you to determine what temperature it is possible to heat the steel $4330 \mathrm{~V}$ in processes such as welding. After the process of heating test samples were tested for structural change, hardness and toughness. Carried out studies have shown a reduction in properties when temperature exceeds $600{ }^{\circ} \mathrm{C}$ during heat treatment. A significant drop in hardness to $275 \mathrm{HV}$ was achieved. As a result of heating at a temperature of more than $800{ }^{\circ} \mathrm{C}$ there has been a hardening of the material in the air.
\end{abstract}

Keywords: steel 4330V; heat treatment; tempering

\section{Wstęp}

Obróbka cieplna stali to bardzo rozległy i skomplikowany dział inżynierii materiałowej. Dzięki procesom obróbki cieplnej można kształtować strukturę oraz własności stali. Daje to duże możliwości wytwórcze produktów stalowych. Niestety, gdy materiał jest dostarczany w stanie gotowym, trzeba przestrzegać zaleceń producenta, aby nie doprowadzić do zmiany własności. Często jest to problem stali z mikrododatkami, które są wytwarzane poprzez specjalne procesy termowalcowania lub też poprzez odpowiednią obróbkę cieplną, która ma zagwarantować własności wytrzymałościowe i plastyczne na bardzo wysokim poziomie [1 $\div 7]$.

Stal $4330 V$ jest stalą obrobioną cieplnie. Posiada w swoim składzie dodatek wanadu, który wpływa na polepszenie własności wytrzymałościowych i plastycznych. Uzyskanie struktury oraz własności wymaga odpowiedniej obróbki cieplnej polegającej na hartowaniu i odpuszczaniu z późniejszym odprężaniem. Cały cykl produkcyjny trwa kilkadziesiąt godzin, a nie właściwe zabiegi cieplne mogą w znaczny sposób pogorszyć własności eksploatacyjne stali. Spawanie jako jeden z procesów łączenia wiąże się z dostarczaniem energii w bardzo krótkim czasie. Ze względu na wysoki równoważnik węgla $(0,89)$ stali $4330 \mathrm{~V}$ uznaje się ją za trudno spawalną. W celu zapewnienia odpowiednich własności złączy konieczne jest zastosowanie podgrzewania wstępnego oraz obróbki cieplnej po spawaniu. W związku z tym istotne jest określenie wpływu obróbki cieplnej na własności mechaniczne i budowę mikrostrukturalną $[7 \div 11]$.

Mgr inż. Marcin Żuk - Politechnika Śląska.

Autor korespondencyjny/Corresponding author. marcin.zuk@polsl.pl 


\section{Badania}

Celem pracy było zbadanie wpływu obróbki cieplnej na własności i strukturę stali 4330V (skład chemiczny i własności badanej stali przedstawiono w tabl. I, II). Stal w stanie dostawy (po obróbce cieplnej) charakteryzuje się mikrostrukturą martenzytu odpuszczonego, rysunek 1. Próbki do badań były docelowo przygotowane pod badania udarności. Przygotowano po 3 próbki na każdą temperaturę wygrzewania.

\section{Obróbka cieplna}

Obróbka cieplna badanej stali polegała na wygrzewaniu próbek (przygotowanych pod próby udarności) w zakresie temperatur od 100 do $900{ }^{\circ} \mathrm{C}\left(\cos 50^{\circ} \mathrm{C}\right)$ w czasie 5 godzin. Piec oporowy zastosowany podczas obróbki nie posiadał atmosfery ochronnej. Próbki nagrzewano z piecem (ok. 30 min) do temperatury docelowej. Po wygrzewaniu były chłodzone wolno w powietrzu.

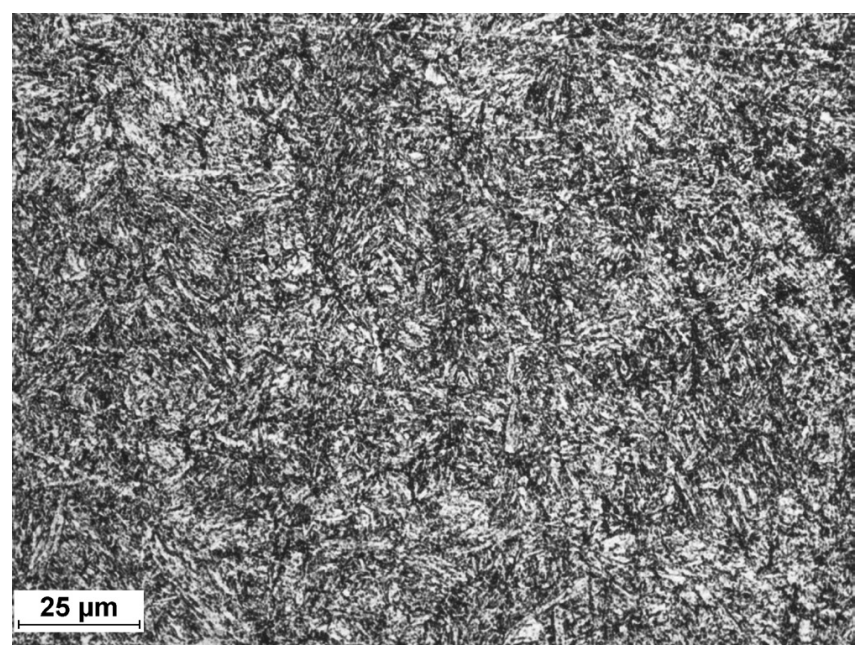

Rys. 1. Mikrostruktura stali $4330 \mathrm{~V}$

Fig. 1. Microstructure of $4330 \mathrm{~V}$ steel

\section{Zakres badań}

Po przeprowadzonej obróbce cieplnej próbki ze stali 4330V zostały poddane badaniom:

- metalograficznym mikroskopowym na mikroskopie świetlnym NIKON ECLIPSE MA100, próbki trawiono nitalem;

- pomiaru twardości metodą Vickersa na urządzeniu Wilson Wolpert 401 MVD. Schemat pomiarów twardości przedstawia rysunek 2;

- próbie udarności metodą Charpy'ego młotem wahadłowym na podstawie wymagań normy PN-EN ISO 148-1. Badanie przeprowadzono $\mathrm{w}$ temperaturze $-40{ }^{\circ} \mathrm{C}$, próbka standardowa $10 \times 10 \times 55 \mathrm{~mm}$ z karbem typu $\mathrm{V}-2 \mathrm{~mm}$.

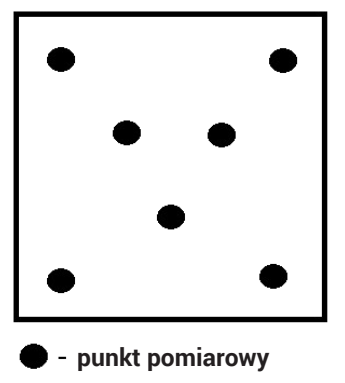

Analiza wyników badań

Uzyskane próbki po obróbce cieplnej różniły się stopniem utlenienia powierzchni (rys. 3). Próbki zostały następnie poddane badaniom mikrostruktury, twardości i udarności. Przeprowadzone badania metalograficzne mikroskopowe (rys. 4) ujawniły występowanie mikrostruktury martenzytu odpuszczonego w materiale rodzimym. W przypadku podgrzewania nie stwierdzono znaczących zmian w strukturze poza niewielkim rozrostem ziarn martenzytu przy podgrzewaniu do temperatury $650{ }^{\circ} \mathrm{C}$. Powyżej temperatury $650{ }^{\circ} \mathrm{C}$ widoczny jest rozrost ziaren martenzytu oraz początek rozpuszczania faz. W próbkach wygrzanych w temperaturze ponad $850^{\circ} \mathrm{C}$ uwidoczniła się typowa struktura martenzytyczna.

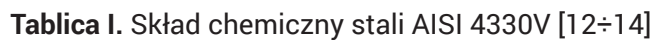

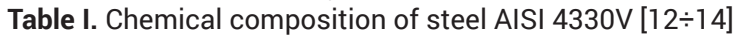

\begin{tabular}{|c|c|c|c|c|c|c|c|c|c|c|c|c|c|}
\hline & \multicolumn{13}{|c|}{ Stężenie wagowe pierwiastków [\%] } \\
\hline & C & $\mathrm{Cr}$ & $\mathrm{Ni}$ & $\mathrm{Mn}$ & Mo & $\mathrm{Si}$ & $P$ & S & $\mathrm{Cu}$ & $\mathrm{Al}$ & $\mathrm{Nb}$ & $\mathrm{Ti}$ & V \\
\hline Norma & $\begin{array}{c}0,3 \\
\div 0,34\end{array}$ & $\begin{array}{l}0,75 \\
\div 1,0\end{array}$ & $\begin{array}{l}1,65 \\
\div 2,1\end{array}$ & $\begin{array}{l}0,75 \\
\div 1,0\end{array}$ & $\begin{array}{c}0,4 \\
\div 0,5\end{array}$ & $\begin{array}{c}0,15 \\
\div 0,35\end{array}$ & $\begin{array}{c}0,035 \\
\max \end{array}$ & $\begin{array}{c}0,035 \\
\max \end{array}$ & $-{ }^{*}$ & $\begin{array}{c}0,015 \\
\div \\
0,035\end{array}$ & $-^{*}$ & $-^{*}$ & $\begin{array}{l}0,05 \\
\div 0,1\end{array}$ \\
\hline $\begin{array}{c}\text { Próbka } \\
-\mathrm{P} 1\end{array}$ & 0,31 & 0,99 & 1,84 & 0,9 & 0,43 & 0,26 & 0,012 & 0,00 & 0,17 & 0,03 & 0,029 & 0,008 & 0,06 \\
\hline
\end{tabular}

Tablica II. Własności stali AISI 4330V [13]

Table II. Properties of steel AISI 4330V [13]

\begin{tabular}{|c|c|c|c|c|}
\hline $\begin{array}{l}\text { Umowna granica } \\
\text { plastyczności } \\
\mathbf{R}_{0,2}{ }^{1}[\mathrm{MPa}]\end{array}$ & $\begin{array}{l}\text { Wytrzymałość na } \\
\text { rozciąganie } \\
\mathrm{Rm}^{1} \text { [MPa] }\end{array}$ & Wydłużenie $A^{1}[\%]$ & $\begin{array}{c}\text { Praca tamania KV } \\
\left(-40^{\circ} \mathrm{C}\right)^{1}[\mathrm{~J}]\end{array}$ & Twardość $[H V]^{1,2}$ \\
\hline 1000 & 1140 & 19 & 89 & 340 \\
\hline
\end{tabular}


Przeprowadzone badania twardości (rys. 5) potwierdziły wyniki badań mikrostruktury, do temperatury ok. $600{ }^{\circ} \mathrm{C}$ twardość badanych próbek jest na poziomie materiału rodzimego (ok. 320 $\div 340 \mathrm{HV}$ ). Powyżej tej temperatury w materiale nastąpiło zmiękczenie do około 275 HV. Próbki obrobione w temperaturze powyżej $800{ }^{\circ} \mathrm{C}$ charakteryzują się twardością na poziomie $500 \mathrm{HV}$.
Badania udarności (rys. 6) wykazały wartość pracy łamania na poziomie $50 \div 70 \mathrm{~J}$ dla próbek wygrzewanych w temperaturze do $600{ }^{\circ} \mathrm{C}$, powyżej tej temperatury zwiększyła się praca łamania do $118 \mathrm{~J}\left(650^{\circ} \mathrm{C}\right)$. Próbki obrobione cieplnie w temperaturze powyżej $650{ }^{\circ} \mathrm{C}$ uzyskały prace łamania na poziomie $20 \div 40 \mathrm{~J}$. Wykonane próby udarności ujawniły w większości prób przełom mieszany (rys. 7) z niewielkim udziałem przełomów kruchych.

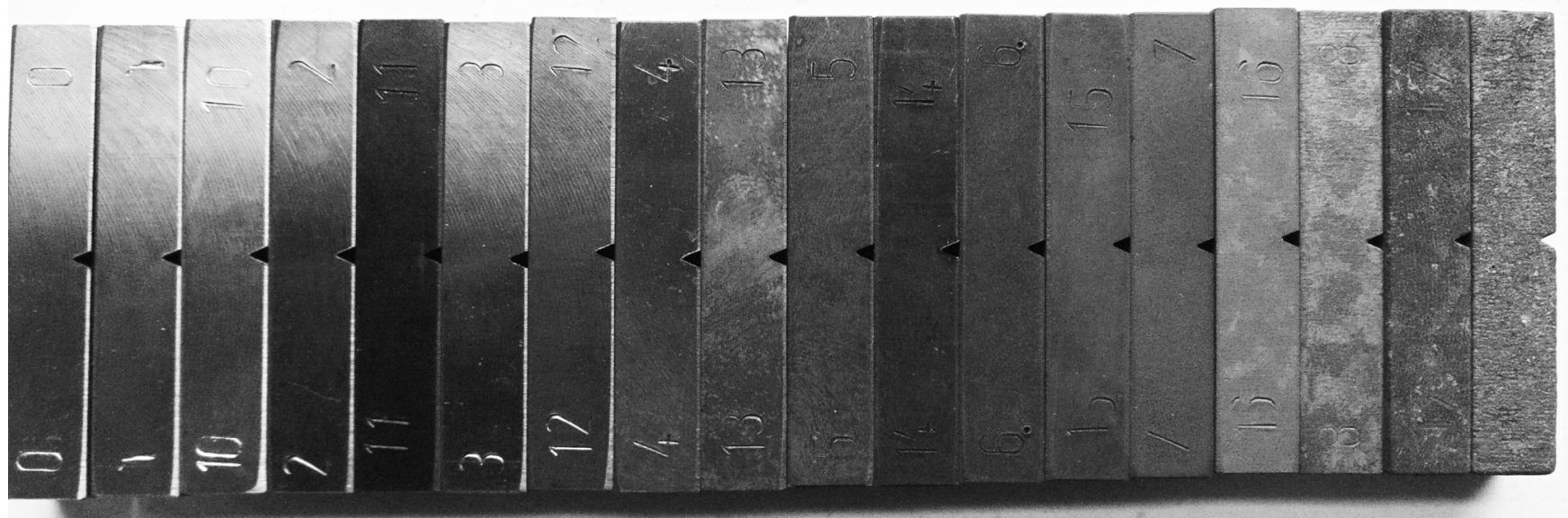

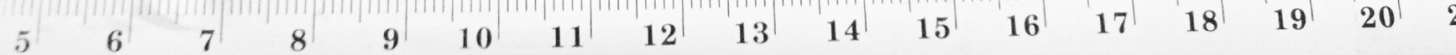

Rys. 3. Próbki po wygrzewaniu

Fig. 3. Samples after heating
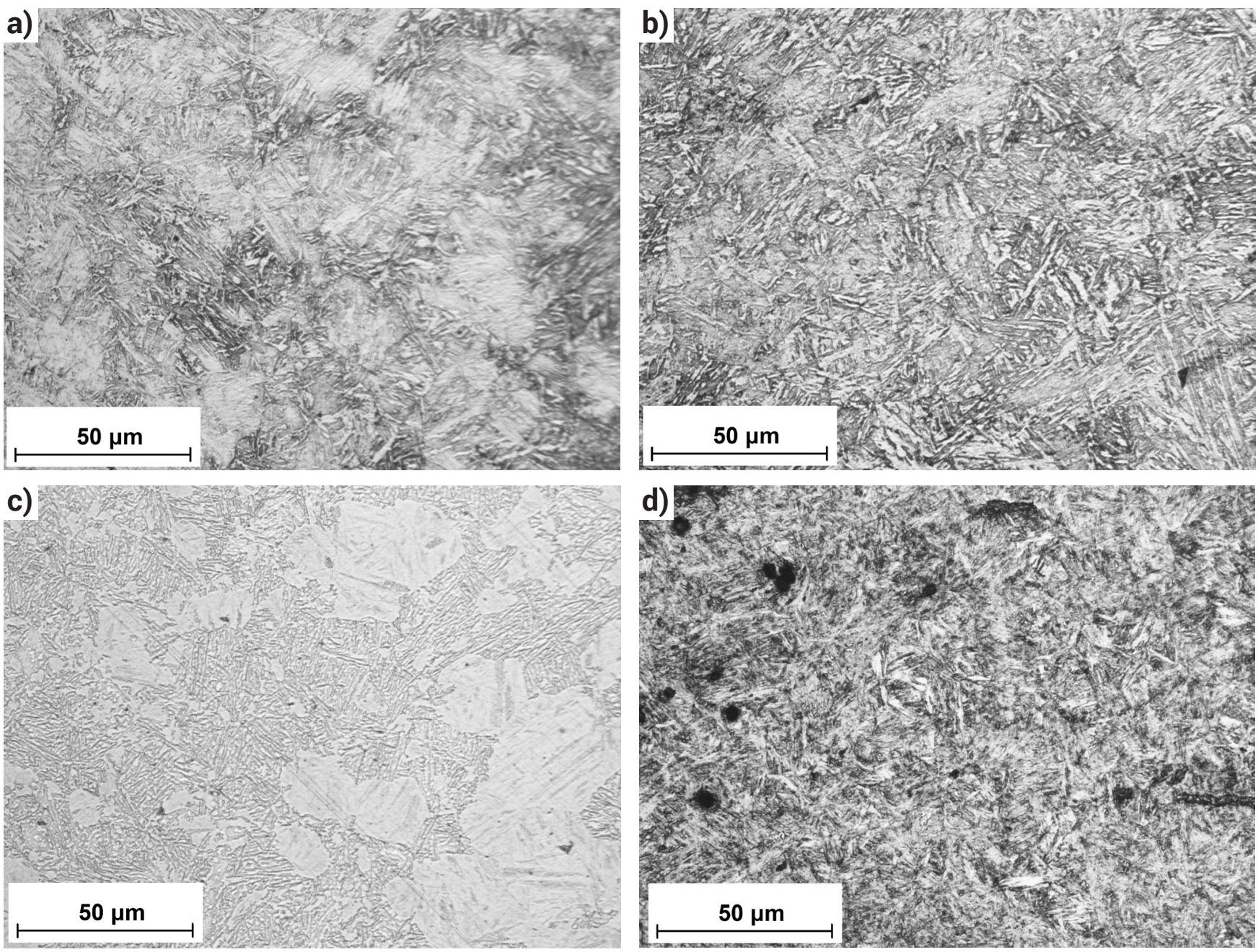

Rys. 4. Mikrostruktura próbek wygrzewanych w temperaturze: a) $150^{\circ} \mathrm{C}$, b) $650^{\circ} \mathrm{C}$, c) $750^{\circ} \mathrm{C}$, d) $900^{\circ} \mathrm{C}$

Fig. 4. Microstructure of samples heating in temperatures: a) $150^{\circ} \mathrm{C}$, b) $\left.650^{\circ} \mathrm{C}, \mathrm{c}\right) 750^{\circ} \mathrm{C}$, d) $900^{\circ} \mathrm{C}$ 


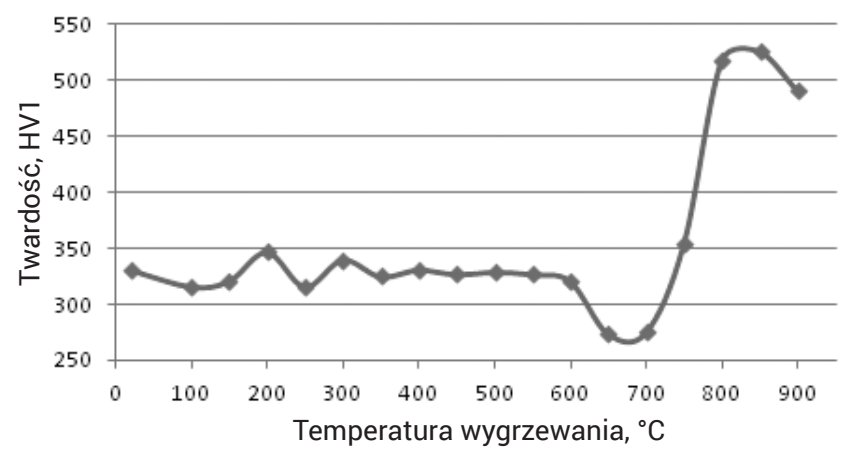

Rys. 5. Wyniki pomiarów twardości

Fig. 5. Results of hardness measurement

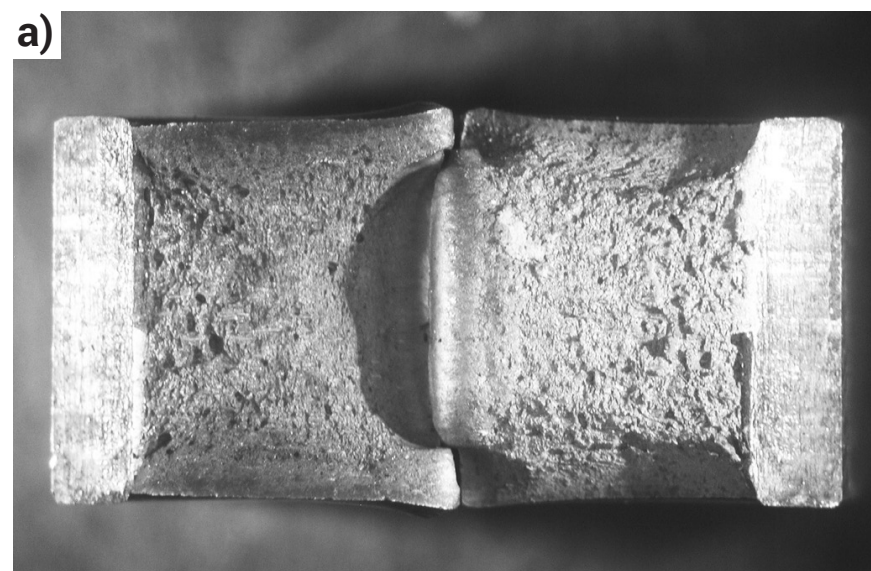

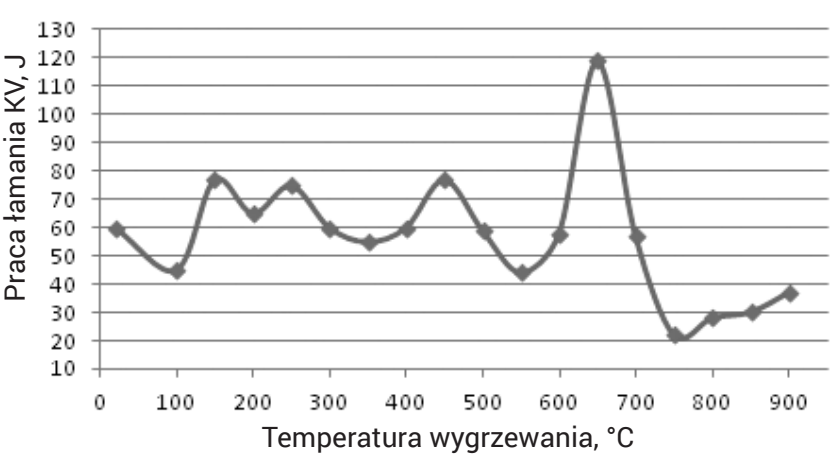

Rys. 6. Wyniki badań udarności

Fig. 6. Impact test results

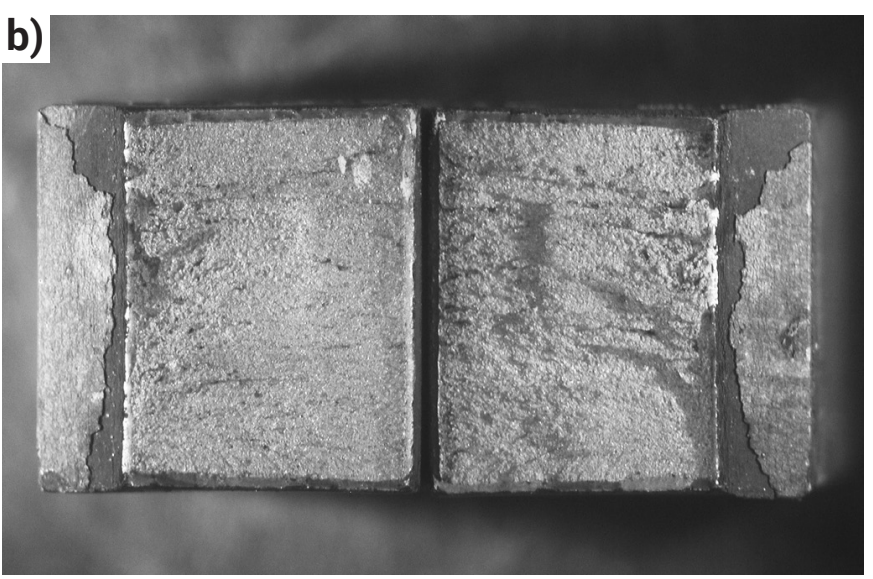

Rys. 7. Próbki po badaniu udarności: a) przełom mieszany, b) przełom kruchy Fig. 7. Charpy V-notch samples after test: a) mixed fracture, b) brittle fracture

\section{Podsumowanie}

Przeprowadzone badania wykazały, że stal 4330V może znaleźć przeznaczenie jako materiał konstrukcyjny w takich obszarach przemysłu jak: wydobywczy ropy i gazu oraz lotnictwo. Uzyskane wyniki potwierdzają, że stal charakteryzuje się bardzo wysoką stabilnością struktury i własności do temperatury $600{ }^{\circ} \mathrm{C}$, co jest zgodne z zaleceniami producenta. Badana stal charakteryzuje się strukturą martenzytu odpuszczonego o twardości ok. $330 \mathrm{HV}$. W wyniku wygrzewania w temperaturze powyżej $650^{\circ} \mathrm{C}$ następuje silne odpuszczenie powodujące obniżenie twardości do poziomu ok. 275 HV (zmiękczenie materiału). Proces wygrzewania w temperaturze powyżej $A_{1}\left(800{ }^{\circ} \mathrm{C}\right)$ powoduje zajście przemiany alotropowej $\mathrm{a} \rightarrow \gamma$, a chłodzenie w powietrzu doprowadza do przemiany martenzytycznej i uzyskania struktury o twardości powyżej $500 \mathrm{HV}$. Wpływ na przemianę martenzytyczną ma bardzo złożony skład chemiczny stali o równoważniku węgla na poziomie 0,89 . Uzyskane wyniki twardości i zmiany struktury potwierdzają badania udarności. W zakresie temperatury obróbki do $600{ }^{\circ} \mathrm{C}$ udarność jest stała (praca łamania ok. $70 \mathrm{~J}$ ), w zakresie temperatury bardzo wysokiego odpuszczania udarność rośnie (praca łamania $118 \mathrm{~J}$ ). W wyniku przemiany martenzytycznej (obróbka powyżej $800^{\circ} \mathrm{C}$ ) udarność stali spada do wartości poniżej dopuszczalnego kryterium (27 J).

\section{Literatura}

[1] S. Rudnik: Metaloznawstwo, Państwowe Wydawnictwo Naukowe, Warszawa $1980 \mathrm{r}$.

[2] K. Przybyłowicz: Metaloznawstwo, Wyd. WNT, Warszawa 2007 r.

[3] J. Adamczyk: Inżynieria wyrobów stalowych, Wyd. Politechniki Śląskiej, Gliwice $2000 \mathrm{r}$.

[4] J. Pacyna, R. Dąbrowski: Wpływ wanadu na przemiany przy odpuszczaniu stali o małej zawartości innych pierwiastków, conference proceedings AMME 2003, s. 713-717.

[5] S. Sackl, M. Zuber, H. Cclemens, S. Primig: Induction tempering vs conventional tempering of a heat-treatable steel, Metallurgical and materials transactions a, vol. 47a.

[6] A. Grajcar, M. Morawiec: Przegląd możliwości zastosowania nowoczesnych stali wysokowytrzymałych do produkcji walcówki na druty, Hutnik 2017 R. 84 nr 1, s. 6-10.

[7] M. Gojić, L. Kosec, P. Matković: The effect of tempering temperature on mechanical properties and microstructure of low alloy $\mathrm{Cr}$ and $\mathrm{CrMo}$ steel, Journal of materials science 33, pp. 395-403.

[8] J. Pilarczyk: Metaloznawstwo spawalnicze, Wyd. Politechniki Warszawskiej, Warszawa 1977r.

[9] J. Pacyna, R. Dąbrowski: Wpływ wanadu na przemiany przy odpuszczaniu stali o małej zawartości innych pierwiastków, 12 th International Scientific Conference. Achivements in mechaanical and material engenering, pp. 713-718.

[10] J. Górka: Własności i struktura złączy spawanych stali obrabianej termoplastycznie o wysokiej granicy plastyczności, Wyd. Pol. Śl., Gliwice 2013.

[11] M. Zuk, J. Górka, A. Czupryński, M. Adamiak: Properties and structure of the weld joints of quench and tempered $4330 \mathrm{v}$ steel, Metalurgija vol. 55 iss. 4, pp.613-616.

[12] AISI 4330V, TATA Steel, 2015r.

[13] Certyfikat jakości stali 4330V.

[14] www.westyorkssteel.com, Karta charakterystyki stali 4330V. 